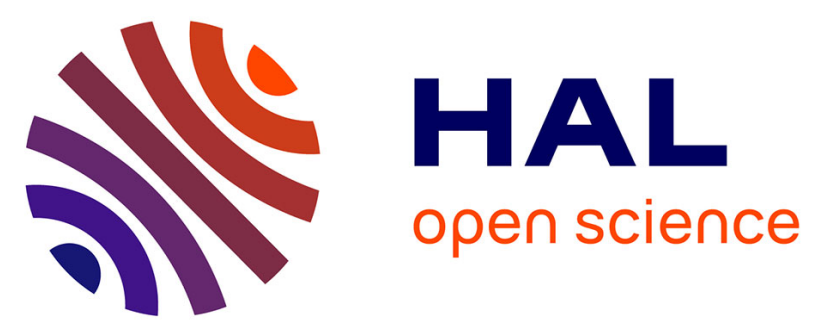

\title{
СТРУКТУРА ВЕРХНЕЙ КОРЫ ПОД ВУЛКАНАМИ КЛЮЧЕВСКОЙ ГРУППЫ ПО ДАННЫМ ШУМОВОЙ ТОМОГРАФИИ
}

I. I. Egorushkin, Ivan Koulakov, Nikolai M Shapiro, Абкадыров И Ф Аннотация

\section{To cite this version:}

I. I. Egorushkin, Ivan Koulakov, Nikolai M Shapiro, Абкадыров И Ф Аннотация. СТРУКТУРА ВЕРХНЕЙ КОРЫ ПОД ВУЛКАНАМИ КЛЮЧЕВСКОЙ ГРУППЫ ПО ДАННЫМ ШУМОВОЙ ТОМОГРАФИИ. ГеоЛогия и геофизика / Russian Geology and Geophysics, 2020, 5, 〈10.15372/GiG2020184〉. 〈hal-03088522〉

\section{HAL Id: hal-03088522 \\ https://hal.science/hal-03088522}

Submitted on 15 Jan 2021

HAL is a multi-disciplinary open access archive for the deposit and dissemination of scientific research documents, whether they are published or not. The documents may come from teaching and research institutions in France or abroad, or from public or private research centers.
L'archive ouverte pluridisciplinaire HAL, est destinée au dépôt et à la diffusion de documents scientifiques de niveau recherche, publiés ou non, émanant des établissements d'enseignement et de recherche français ou étrangers, des laboratoires publics ou privés. 


\title{
СТРУКТУРА ВЕРХНЕЙ КОРЫ ПОД ВУЛКАНАМИ КЛЮЧЕВСКОЙ ГРУППЫ ПО ДАННЫМ ШУМОВОЙ ТОМОГРАФИИ
}

\author{
И. И. Егорушкин (1), И. Ю. Кулаков $(1,2,3)$, Н. М. Шапиро (4, 5), Е. И. Гордеев (3),
} А. В. Яковлев (1,2), И. Ф. Абкадыров (3)

1. Институт нефтегазовой геологии и геофизики СО РАН им. А.А. Трофимука, Новосибирск

2. Новосибирский государственный университет

3. Институт вулканологии и сейсмологии ДВО РАН, Петропавловск-Камчатский

4. Institut des Sciences de la Terre (ISTERRE), UMR CNRS 5375, Université Grenoble-Alpes, Grenoble, France

\section{5. Институт физики Земли РАН им. О.Ю. Шмидта, Москва}

\section{ВВЕДЕНИЕ}

Ключевская группа вулканов расположена на полуострове Камчатка и имеет площадь порядка 50х80 км. К Ключевской группе относят более десяти крупных вулканических построек, а также множество моногенных конусов и других вулканогенных структур. По разнообразию продуктов извержений, размерам вулканов и интенсивности эруптивной активности, Ключевская группа является уникальным вулканическим комплексом, не имеющим аналогов в мире [Лаверов и др., 2005; Пономарева и др., 2008; Федотов и др., 2010]. Три вулкана группы, Ключевской, Безымянный и Толбачик (включающий Острый и Плоский Толбачик, а также Толбачинский Дол), которые относятся к наиболее активным вулканам мира, имеют принципиально различные режимы эруптивной активности и составы изверженных пород, о чем более подробно будет изложено в следующем разделе.

Для изучения причин такого разнообразия и интенсивности протекающих в вулканах Ключевской группы процессов, было выполнено множество различных геологогеофизических исследований. Обобщив существующий петрологический материал, Добрецов и др. [2012] показали, что особенности вулканизма Ключевской группы определяются наличием системы многоуровневых магматических источников в коре и мантии над погружающимся Тихоокеанским слэбом.

При определении строения глубинных источников магматической активности особую роль играют многомасштабные сейсмологические исследования, которые в 
настоящем регионе проводятся достаточно активно. Ключевская группа относительно неплохо покрыта сетью телеметрических сейсмических станций Камчатского филиала федерального исследовательского центра единой геофизической службы РАН (КФ ФИЦ ЕГС РАН), количество которых в некоторые годы доходило до 25 [Чебров и др., 2013]. Эта сеть предоставляет непрерывные наблюдения за сейсмичностью в коре и мантии в течение нескольких последних десятилетий. Кроме этого, в последние годы в районе Ключевской группы были установлены несколько временных сейсмических сетей, которые позволили более детально исследовать отдельные вулканические структуры. Записи с постоянных и временных сетей, а также глобальные каталоги сейсмических данных, были использованы в ряде исследований для построения моделей строения коры и мантии под Ключевской группой.

Форма и структура погружающейся Тихоокеанской плиты были изучены в работах [Gorbatov et al., 2001; Jiang et al., 2009; Кулаков и др., 2011] при помощи региональных версий алгоритма сейсмической томографии с использованием глобальных каталогов сейсмологических данных. Структура мантийного клина исследовалась на базе использования данных КФ ФИЦ ЕГС РАН по региональной сейсмичности в работах [Gorbatov et al., 1999; Низкоус и др., 2006, Кулаков и др., 2016]. В работе Кулакова и др., [2016] была обнаружена вертикальная низкоскоростная аномалия под вулканом Кизимен, соединяющая его с погружающимся слэбом. Так же авторы данной статьи выявили под Ключевской группой вулканов серию наклонных скоростных аномалий и выдвинули предположение, что именно эти аномалии определяют многообразие магматических проявлений в данном районе.

Данные постоянных станций КФ ФИЦ ЕГС РАН были также использованы во множестве исследований для изучения структуры коры под вулканами Ключевской группы [Славина и др., 2001; Хубуная и др., 2007, Lees et al., 2007, Koulakov et al., 2011; 2013]. В этих работах была выявлена крупная аномалия с высоким значением отношения Vp/Vs на подошве коры непосредственно под Ключевским вулканом, которая совпадает с постоянно действующим кластером длиннопериодной сейсмичности на глубинах 25-30 км [Shapiro et al., 2017a]. В работе Koulakov et al. [2013] были выполнены повторные построения томографических моделей за несколько лет наблюдения, и данная аномалия оставалась практически неизменной во времени. В средней и верхней коре также наблюдались аномалии с высоким отношением $\mathrm{Vp} / \mathrm{Vs}$, которые связывались с промежуточной и малоглубинной магматическими камерами, свойства которых существенно менялись во времени синхронно с протекающей эруптивной активностью Ключевского и Безымянного вулканов. Такие быстрые изменения сейсмических свойств связывались авторами с 
миграцией флюидов, которые способны кардинальным образом изменить степень плавления в магматическом резервуаре.

Станции КФ ФИЦ ЕГС РАН, прежде всего, нацелены на мониторинг Ключевского и Безымянного вулканов. Они относительно плотно покрывают эти вулканы с разных сторон, что позволило получить достаточно детальные и достоверные томографические модели, упомянутые выше. Вместе с тем для других вулканов группы покрытие постоянными станциями не столь удачное. В связи с этим был организован ряд кампаний по установке временных сетей в отдельных частях Ключевской группы. Так, в районе Толбачинского вулканического комплекса в 2014-2015 годах функционировала сеть из 24 временных станций, данные с которой позволили существенно уточнить структуру коры под Толбачиком и всей Ключевской группой [Koulakov et al., 2017]. В частности, в этой работе были обнаружены следы нескольких подводящих каналов под Плоским Толбачиком и Толбачинским долом, которые доказали, что извержения там питаются из различных глубинных источников. Следует упомянуть также временную сеть из четырех станций, установленную на три месяца в районе вулкана Удина, с помощью которой удалось показать наличие активного магматического источника под этим вулканом, ранее рассматриваемым как полностью потухший [Koulakov et al., 2019].

В 2015-2016 годах был проведен международный эксперимент KISS, в рамках которого в районе Ключевской группы вулканов была развернута масштабная сеть сейсмических станций [Shapiro et al., 2017b] (рис. 1a). Вместе с 17 постоянными станциями КФ ФИЦ ЕГС РАН, объединенная сеть включала в себя более сотни одновременно работающих станций. Обработка такого объема информации потребовала достаточно длительного времени, поэтому только сейчас стали появляться первые результаты. Относительно равномерное расположение станций этой сети делает эффективным использование метода шумовой томографии для изучения структуры верхней коры. Это представляется особенно важным, принимая во внимание, что методики, основанные на объемных волнах [например, использованные в работах Koulakov et al., 2011, 2017] не могут обеспечить достаточного перекрытия лучей в верхней части коры (до глубин 3-5 км), вследствие чего получить там хорошее разрешение невозможно. Модели, рассчитанные на базе использования данных по поверхностным волнам, в этом смысле успешно дополняют результаты, полученные на основе объемных волн.

Первая сейсмическая модель, построенная с использованием данных сети KISS,

102 была получена в работе Green et al. [2020] путем выполнения интерферометрии 103 сейсмического шума и применения методов поверхностноволновой томографии. Для 104 инверсии в этой модели был использован метод Монте-Карло, позволяющий перебирать 
конфигурации нерегулярной сетки и скорости в ней в большом количестве моделей, из которых в конечно итоге выбирается модель, обеспечивающая наилучшее совпадение с данными. В этом случае, как утверждают авторы, рассчитанная модель не зависит от стартовой скорости и поэтому обеспечивает сходимость к решению с абсолютным минимумом функционала невязок данных. Вместе с тем модель, представленная в работе

110 Green et al. [2020], выглядит излишне сглаженной, и создается впечатление, что 111 предложенная авторами схема не самым оптимальным образом использует имеющиеся 112 данные, из которых можно было бы извлечь более детальную информацию о строении 113 изучаемой области. По этой причине мы решили повторить эту работу с использованием других методик. По ходу работы мы самостоятельно провели корреляцию шума, выделив тем самым из него поверхностные волны, построили на основе этих волн дисперсионные 116 кривые и провели для них инверсию на основе собственного алгоритма 117 поверхностноволновой томографии.

118 Кроме этого, данные KISS послужили основой для построения новой модели скоростей P- и S-волн в коре и мантии на основе использования объемных волн от локальных землетрясений [Koulakov et al., 2020]. В верхней коре эта модель выявила явное соответствие между распределением сейсмических аномалий и основными вулканическими структурами Ключевской группы вулканов. Сравнение наших результатов с этой моделью, полученной на основе принципиально иного подхода, является важным шагом для проверки достоверности выявляемых структур. полуострова внутри Центрально-Камчатской депрессии, которая сформировалась в результате рифтовых процессов [Alexeiev et al. 2006; Avdeiko et al., 2007; Певзнер и др.,

130 2017]. КГВ расположена западнее Восточного вулканического фронта, который 131 представляет собой основную вулканическую дугу, связанную с субдукцией

132 Тихоокеанской плиты. Субдуцирующая Тихоокеанская плита расположена под КГВ на 133 глубине около 150 км, что несколько глубже, чем обычно наблюдается для вулканических 134 дуг. КГВ находится вблизи края Тихоокеанской плиты, который четко отслеживается на 135 результатах региональной томографии [Кулаков и др., 2011]. Наличие «окна» между 136 субдуцирующими плитами Алеутского и Камчатского сегментов называют одной из 137 причин аномального прогрева мантийного клина, вызвавшего особый характер вулканизма 138 в этом районе [Yogodzinski et al. 2001]. Другой возможной причиной может быть субдукция 139 симаунтов Императорского хребта, являющегося древним продолжением цепочки 
140 Гавайских вулканов, что могло вызвать особый состав вещества и аномальное количество 141 летучих в системе [Portnyagin et al., 2005; Dorendorf et al. 2000].

142 КГВ включает в себя 13 близко расположенных друг к другу действующих, спящих 143 и потухших вулканов (рис. 1b). Вместе с отдельно стоящим вулканом Шевелуч и 144 несколькими потухшими вулканическими постройками в Центрально-Камчатской 145 депрессии, эту область называют Северной группой вулканов. Севернее Шевелуча на 146 Камчатке активных вулканов нет. В течение последней сотни тысяч лет вулканы КГВ 147 извергали в среднем 1 кубический метр пород в секунду [Федотов и др., 2010]. Общий 148 объем изверженных вулканами группы пород превосходит суммарный объем пород, изверженных всеми остальными вулканами Камчатки.

Главный вулкан группы, Ключевской, имеет высоту 4750 метров и является наиболее высоким активным вулканом в Евразии. Его активность проявляется в виде 152 относительно спокойных извержений с периодичностью 2-4 года, во время которых 153 происходит излияние высокомагнезиальных базальтов из вершинного кратера и более чем 15480 побочных конусов [Хренов и др., 1991; Ozerov et al., 2007]. Интересной особенностью 155 активности Ключевского вулкана является то, что практически постоянно непосредственно 156 под ним на глубине около 25-30 км происходит множество достаточно сильных длиннопериодных землетрясений [Shapiro et al., 2017b]. Предполагается, что эти

158 землетрясения маркируют положение глубинного очага, расположенного у подошвы коры, 159 который питает текущие извержения Ключевского вулкана [Koulakov et al., 2011, 2013, 160 2017].

Безымянный вулкан, расположенный на расстоянии всего 10 км от Ключевского, 163 в 1956 году произошло катастрофическое взрывное извержение, которое наполовину 164 разрушило конус этого вулкана [Богоявленская и др., 1991]. После этого извержения вулкан 165 Безымянный эпизодически, примерно раз в год, производит взрывные извержения, которые 166 длятся всего несколько десятков минут и выбрасывают в атмосферу пепел и газы на высоту 167 до двух десятков километров [Girina, 2013]. Внутри кальдеры, образовавшейся после 168 катастрофического извержения 1956 года, в течение последних десятилетий растет 169 активный конус, размеры которого постепенно доходят до размера уничтоженной во время взрыва части вулканической постройки Безымянного [Van Manen et al., 2010].

Третий действующий вулкан группы, Толбачик, представляет собой комплекс из 172 двух крупных вулканических построек, Плоского и Острого Толбачика высотой 3085 и 1733682 метров соответственно, и обширной территории на юге, называемой Толбачинским 174 долом. Последнее трещинное извержение вулкана Толбачик случилось в 2011-2012 годах. 
175 Во время него происходило излияние больших объемов маловязких базальтовых лав, 176 которые растекались по большой площади на расстояния в десятки километров [Belousov 177 et al., 2015]. Аналогичные по размерам трещинные извержения в Толбачинском долу имели 178 место в 1975-1976 годах, в 1941 году и ранее [Федотов, 1984]. Несколько исторических 179 извержений аналогичного типа было зарегистрировано в районе Плоского Толбачика, 180 например, в 1939 и в 1975 году. Последнее извержение примечательно обрушением кратера

181 и тем, что оно произошло одновременно с трещинным извержением в Толбачинском долу 182 [Федотов, 1984]. Имеются свидетельства, полученные с помощью геохимии [Churikova et 183 al., 2015], что извержения различных сегментов Толбачинского дола (Южный и Северный прорывы) и Плоского Толбачика питаются из различных источников, что также подтверждается результатами томографии [Koulakov et al., 2017]. Одним из источников магмы толбачинских извержений называют глубинную магматическую камеру под

187 Ключевским вулканом, другим - зону Толуд на юго-востоке от Плоского Толбачика, где 188 регистрируется значительное количество землетрясений в нижней и средней коре 189 [Салтыков и др., 2018].

Помимо указанных трех действующих вулканов следует упомянуть гигантский вулканический массив на западе от Ключевской сопки, который объединяет в себе два сросшихся вулкана: Ушковский высотой 3943 м и Крестовский высотой 4108 м. Этот массив образовался 50-60 тысяч лет назад и на начальной стадии представлял собой

194 крупный щитовой базальтовый вулкан [Флеров, Овсянников, 1991; Флеров и др., 2017]. В 195 настоящее время вулкан Крестовский представляется полностью потухшим, а Ушковский 196 проявляет небольшую фумарольную и сейсмическую активность и рассматривается как спящий [Овсянников и др., 1985].

Другим интересным объектом в Ключевской группе является вулкан Удина, который до 2017 считался полностью потухшим. Однако начиная с декабря 2017 года, в

200 районе этого вулкана стали регистрировать постепенно нарастающую сейсмическую активность [Салтыков и др., 2018; Кугаенко и др., 2020]. Благодаря установке четырех сейсмических станций на вулкане в период кризиса, были определены точные положения гипоцентров более 300 событий, а также построена модель распределения скоростей сейсмических волн под вулканом [Koulakov et al., 2019]. Эти результаты указали на признаки активизации магматической камеры под Удиной на глубине около 6 км.

Сеть KISS была развернута в рамках международного объединения исследователей из России, Франции и Германии [Shapiro et al., 2017b]. Сейсмические станции были 
210 установлены на площади 120х70 км, включающей в себя Ключевскую группу вулканов с

211 окружающей её частью Центрально-Камчатской депрессии и доходящей до вулкана

212 Кизимен на юге. Станции были установлены в августе-сентябре 2015 года и сняты в июле

2132016 года. Некоторое количество станций было транспортировано до точек наблюдения

214 автомобильным транспортом, однако большая часть из них была установлена в

215 труднодоступных местах, куда была доставлена легким вертолетом Робинсон. Временные

216 станции устанавливались с учетом расположения 17 перманентных станций КФ ФИЦ ЕГС

217 РАН. Временная сеть включала в себя 30 сенсоров 30 Trillium Compact (с максимальным

218 периодом колебаний до 120 c), 6 сенсоров Guralp CMG-6T (30 c), 8 сенсоров Guralp CMG-

219 6TD (30 c), 9 R-Sensors CME-4111 и 30 Mark L-4C-3D с номинальным максимальным

220 периодом 1 с. Следует отметить, что для сенсоров Mark L-4C-3D ранее было показано, что

221 несмотря на указанную границу частотного диапазона, они стабильно регистрируют сигнал

222 с периодом до 20 секунд, что позволяет также использовать их для выполнения шумовой

223 томографии. В сумме, в рамках сети KISS одновременно функционировали 50

224 широкополосных станций, 27 станций с промежуточными частотными характеристиками и

22528 короткопериодных прибора. B работе Green et al. [2020] были использованы данные по

226 всем станциям широкого и промежуточного диапазона. В нашем исследовании, поскольку

227 основной интерес представляли вулканические структуры, мы ограничились только

228 станциями, расположенными на территории КГВ (рис. 1а). Всего в данной работе были

229 использованы записи 37 станций, что теоретически дает 666 пар приемников,

230 соответствующих лучам в шумовой томографии. Однако после отбора кондиционных

231 данных количество лучей, выбранных для томографии, было существенно меньше.

232 При обработке данных мы использовали обычный набор процедур, применяемых 233 другими авторами для выполнения шумовой томографии [Shapiro et al., 2005; Campillo et

234 al., 2011]. Прежде всего, данные по каждой станции были скорректированы с помощью

235 файлов отклика (response files), имеющихся для каждой станции. Эта процедура позволяет

236 привести станции с различными свойствами к одинаковому отклику на одно и то же

237 событие. Записи на станциях производились с частотой 50 или 100 измерений в секунду. В

238 нашем случае для всех записей частота дискретизации была понижена до 10 Гц

239 (downsampling). После этого была проведена процедура спектрального отбеливания

240 (spectral whitening), позволяющая убрать некоторые доминирующие частоты и усилить

241 части спектра, которые в исходной записи имеют низкую амплитуду, но являются важными

242 для дальнейшего анализа. Для того, чтобы убрать высокоамплитудные сигналы, связанные

243 с землетрясениями, реализуется процедура однобитной нормализации (one-bit

244 normalization), согласно которой исходная гладкая сейсмограмма заменяется на дискретную 
запись со значениями 1 и -1 в соответствии со знаком исходного сигнала. Далее проводится кросс-корреляция сигналов, соответствующих паре станций. Полученная в результате этой процедуры коррелограмма соответствует сейсмическому сигналу, генерируемого одной из станций в качестве виртуального источника и регистрируемого другой. Наиболее четкими на этой записи проявляются поверхностные волны, которые можно использовать для дальнейшей томографической процедуры. В нашем случае мы реализовали корреляцию только для вертикальных колебаний приемника (Z-канала), в результате чего мы получили записи волн Рэлея. Корреляция производилась для участков сейсмограмм продолжительностью 24 часа. Все полученные коррелограммы затем суммировались по всему времени одновременной работы соответствующих пар станций. Итоговые суммарные коррелограммы для всех пар используемых в работе станций приведены на (рис. 2).

Далее выполняется анализ полученных на суммарных коррелограммах записей поверхностных волн и построение на их основе дисперсионных кривых групповых скоростей. Для этого используется алгоритм частотно-временного анализа (Frequency-time analysis, FTAN), разработанный [Levshin et al., 1989; Ritzwoller and Levshin 1998]. На первом этапе производится осреднение положительной и отрицательной частей коррелограммы, соответствующих волнам, идущих от одной станции к другой и обратно. После этого проводится фильтрация полученной коррелограммы серией узкополосных фильтров с периодами от 1 до 10 секунд. Полученные спектры выстраиваются на едином графике с координатами кажущаяся скорость - период. Максимум амплитуды спектра на каждом периоде показывает значение групповой скорости на данной частоте. Для всех пар станций строились такие зависимости и делались попытки провести дисперсионные кривые по максимумам объединенного спектра. Для пикирования дисперсионных кривых использовался алгоритм, разработанный [Mordret A., Landès M., 2013] (рис. 3). Для некоторых пар станций однозначно определить точки максимумов спектра было невозможно в силу низкого уровня сигнал/шум, и такие данные отбрасывались. Даже там, где дисперсионная кривая относительно неплохо прослеживалась, на малых периодах определение положения кривой было затруднено наличием множества мод, а на высоких периодах - слишком плоской формой спектра. По этой причине, подавляющее

275 большинство дисперсионных кривых было снято для диапазона периодов 2-7 секунд. 276 Входными данными для нашего томографического алгоритма являются файлы, 277 содержащие значения групповых скоростей волн Рэлея для фиксированного периода и 278 координаты отвечающих им пар станций. Таким образом, всего в работе было использовано 2796 файлов. Количество и конфигурация лучей для каждого периода приведены в (табл. 1) и 
на (рис. 4) соответственно. Цвет каждого луча на (рис. 4) отвечает величине отклонения от среднего значения групповой скорости для данного периода. Можно выделить некоторые регулярные особенности, которые показывают наличие высоко- и низкоскоростных областей в изучаемой области.

АЛГОРИТМ ШУМОВОЙ ТОМОГРАФИИ И РЕЗУЛЬТАТЫ

В настоящем исследовании томографическая инверсия осуществляется с помощью алгоритма, описанного в статье [Koulakov et al., 2016] с некоторыми модификациями. Процедура состоит из двух этапов: построения двумерных карт групповых скоростей для отдельных частот и инверсии на их основе для получения трехмерного распределения скорости поперечных волн (Vs).

\section{Карты групповых скоростей.}

Построение карт групповых скоростей основано на итеративном повторении процедур лучевого трассирования и инверсии. Для каждой отдельной частоты (периода) для всех пар станций строятся лучи поверхностных волн с учетом рельефа и распределения групповой скорости. С этой целью разработан специальный алгоритм лучевого трассирования методом изгиба, подробно описанный в работе [Koulakov et al., 2017], который подразумевает постепенный изгиб луча и поиск траектории с минимальным временем пробега. Примеры построения лучей для первой и пятой итерации для одной из частот показаны на (рис. 5a, b). Отметим, что даже в стартовой модели лучи не являются прямыми линиями из-за влияния рельефа (см., например, луч, отмеченный синим, на рис. 5a, b). При наличии высоких резких гор, как в нашем случае, поверхностная волна имеет меньшее время пробега, если проходит вокруг горы, а не по ее поверхности. регулярной сетке на расстоянии 2 км друг от друга в местах, где плотность лучей превосходит некоторый порог - 10\% от среднего значения (рис. 5c). Между узлами скорость аппроксимируется с помощью билинейной интерполяции. Чтобы минимизировать влияние геометрии сетки на результат, производится серия независимых инверсий по сеткам с различными базовыми ориентациями $(0,22,45$ и 66 градусов), результаты которых затем усредняются и сводятся в одну модель.

Стартовая модель при расчете невязок - постоянная скорость, которая определяется

310 для каждой частоты таким образом, чтобы суммарные невязки времен по лучам были равны

311 нулю. При этом, если максимальная невязка превосходит заданный порог (2 секунды в 312 нашем случае), то этот луч отбрасывается, и средняя скорость вычисляется заново.

313 Процедура повторяется до тех пор, пока все невязки не оказываются ниже порогового 314 значения. Значения средних скоростей для каждого периода приведены в (табл. 1). 
Инверсия осуществляется путем решения системы линейных уравнений методом

316 LSQR [Paige and Saunders, 1982; Nolet, 1987]. Сглаживание модели и амплитуда аномалий 317 контролируется путем добавления дополнительных уравнений, которые позволяют 318 минимизировать либо разницу значений аномалий в соседних узлах, либо амплитуду 319 решения в каждом узле.

320 После выполнения инверсии производится трассирование лучей в новой двухмерной модели, считаются новые невязки, рассчитывается матрица чувствительности и проводится инверсия. Общее количество итераций в нашем случае равнялось пяти. Результаты инверсии групповых скоростей для различных периодов показаны на (рис. 6). Наблюдаются существенные изменения структур аномалий в зависимости от периода. Принимая во внимание, что с ростом частоты максимальная чувствительность групповых скоростей волн

326 Рэлея достигается на больших глубинах, можно сказать, что скоростная структура в 327 изучаемой области существенно меняется как в латеральном направлении, так и по глубине. 328 Интерпретация этой модели с точки зрения геологического строения представлена в разделе «Обсуждение результатов».

\section{Оптимизация одномерной модели Vs.}

Двумерные модели групповых скоростей, построенные на предыдущем этапе, служат основой для построения трехмерной модели скорости поперечных волн (Vs). Перед реализацией трехмерной инверсии, производится оптимизация референтной одномерной модели Vs(z). Для этого строится осредненная дисперсионная кривая, состоящая из средних значений групповой скорости на каждой из частот, указанных в (табл. 1). Оптимизация одномерной модели выполняется с помощью итеративной процедуры инверсии. Для заданной стартовой скоростной модели $\mathrm{Vs}(\mathrm{z})$ рассчитывается модельная дисперсионная кривая с помощью алгоритма прямого моделирования, разработанного [Herrmann, 1987]. Разница между модельными и наблюдаемыми групповыми скоростями на дисперсионной кривой формирует вектор данных. Для данной референтной модели путем применения расчетов по схеме Herrmann [1987] рассчитывается матрица чувствительности $\mathrm{A}_{\mathrm{ij}}$, показывающая, насколько вариация скорости на i-м уровне $d V s_{i}$ влияет на изменение групповой скорости на $\mathrm{j}$-й частоте, $\mathrm{dU}$. $A_{i j}=d U_{j} / d V s_{i}$

Графическое представление этой матрицы в виде кривых чувствительности показано на (рис. 7). Можно видеть, например, что на первой итерации для волны с периодом 2 с максимальная чувствительность достигается на глубине 0.5 км, для 3 с -1.5 км, для 4 с - 2 км, для $5 \mathrm{c}-3$ км; для $6 \mathrm{c}-4$ км и для $7 \mathrm{c}-6$ км. Максимальная глубина, на которой имеется чувствительность на низких частотах оценивается около 8 км. 
Решение системы линейных уравнений производится с помощью алгоритма LSQR

351 [Paige and Saunders, 1982; Nolet, 1987] с включением дополнительных блоков для сглаживания модели и амплитудного демпинга. В нашем случае коэффициенты сглаживания и амплитудного демпинга составляли 5 и 5 соответственно. Полученные после

354 инверсии аномалии добавлялись к референтной модели (тонкая черная линия на рис. 8), в 355 которой рассчитывается новая дисперсионная кривая и новые значения матрицы 356 чувствительности. После этого производилась инверсия и расчет новой модели. В нашем случае в общей сложности производилось пять итераций. Финальная скоростная модель и соответствующая ей дисперсионная кривая показаны на (рис. 8) красной линией. Как видно, полученная дисперсионная кривая не совсем идеально ложится на наблюдаемую кривую. Мы пробовали разные значения параметров сглаживания и обнаружили, что при их меньших значениях (например, 1) восстановление дисперсионной кривой производилось почти идеально. Однако полученная при этом скоростная модель имела резкие вариации скорости, которые привели бы к нереалистичным структурам в финальной модели; поэтому мы выбрали более консервативную оценку для стартовой скорости.

Важным этапом является проверка вертикального разрешения, обеспечиваемого данной системой наблюдения. Изначально мы не ожидали высокого вертикального разрешения, поскольку использовали дисперсионные кривые только на шести периодах с относительно небольшим диапазоном. Это не дает достаточного количества уравнений для восстановления детальных структур по глубине. На (рис. 9) приведен пример синтетического моделирования, направленного на оценку вертикального разрешения в рассматриваемом случае. В качестве референтной модели мы выбрали распределение, полученное для реальных данных. На эту скоростную модель мы накладывали слои толщиной 2 км с чередующимися положительными и отрицательными аномалиями с амплитудой $\pm 7 \%$. В этой модели была рассчитана дисперсионная кривая (синяя линия на рис. 9c). Дисперсионная кривая в стартовой модели существенно отличается от кривой в истинной модели. После нескольких итераций процедура привела к решению, показанному красной линией на (рис. 9с), которое достаточно точно накладывается на «наблюдаемые» значения. При этом исходные и восстановленные скорости и аномалии показаны на (рис. 9а и b) соответствующими цветами. Как и ожидалось, идеального восстановления слоев не получилось, однако основные вариации до глубины 5-6 км определяются корректно.

381 Ограничения вертикального разрешения, продемонстрированные данным тестом, должны 382 приниматься во внимание при интерпретации результатов инверсии реальных данных. 
Для построения трехмерной модели Vs, в каждой точке области (x, y) строится локальная дисперсионная кривая по значениям групповых скоростей в двумерных моделях, соответствующих различным частотам. Согласно алгоритму оптимизации, описанному в предыдущем разделе, можно построить одномерную модель Vs(z) в текущей точке области.

388 Выполнив аналогичную процедуру для всех точек области, можно построить трехмерную 389 модель $\mathrm{Vs}(\mathrm{x}, \mathrm{y}, \mathrm{z})$. В настоящей работе инверсия проводится одновременно для всех точек 390 области. При этом накладываются дополнительные условия не только на сглаживание 391 скорости в вертикальном, но и в горизонтальном направлении. Для этого добавляются 392 дополнительные уравнения, обеспечивающие минимизацию разницы значений скорости в 393 соседних узлах, расположенных на одной глубине. При одновременной инверсии 394 коэффициент сглаживания в вертикальном направлении составлял 0.2 , а в горизонтальном 395 - 0.3. Регуляризация по амплитуде не производилась.

396 После расчета трехмерной скоростной модели, осуществлялся расчет невязок между 397 модельными и наблюдаемыми групповыми скоростями в каждой точке, и строилась новая 398 матрица чувствительности с учетом обновленных значений $\operatorname{Vs}(\mathrm{z})$ в каждой точке области 399 (х, у). Далее производилась инверсия и строилась новая скоростная модель. Всего было 400 выполнено пять итераций.

401 Горизонтальные и вертикальные сечения трехмерной модели, полученной в 402 результате инверсии, показаны на (рис. 10, 11 и 12). Следует отметить, что горизонтальные 403 сечения не являются в строгом смысле таковыми, поскольку глубина для них отсчитывается 404 от дневной поверхности и следует вдоль рельефа. При этом, чем больше глубина сечения, 405 тем более сглаженным для него представляется референтный рельеф, что обусловлено тем, 406 что информацию о больших глубинах дают низкочастотные поверхностные волны, которые 407 менее чувствительны к резким изменениям рельефа. На (рис. 10 и 11) показаны аномалии $408 \mathrm{dVs}$ относительно одномерной референтной модели на горизонтальных и вертикальных 409 сечениях соответственно, а на (рис. 12) - абсолютные скорости на вертикальных сечениях. 410 Ранее было отмечено, что при оптимизации Vs(z) мы приняли решение использовать более 411 сглаженную модель скорости, которая при этом не обеспечивала идеальное совпадение с 412 дисперсионной кривой. В связи с этим при инверсии на некоторых глубинах скоростные 413 аномалии оказывались не идеально сбалансированными и сдвинутыми в положительную 414 или отрицательную сторону. Поэтому для каждой глубины мы представляем отдельную 415 цветовую шкалу, в которой переход от «синего» до «красного» цвета не всегда совпадает с 416 нулем аномалии. На всех сечениях результаты показаны только там, где суммарная 417 величина чувствительности является не менее $1 \%$ от средней суммарной чувствительности 
418 по всей области. Таким образом, в местах, где нет данных или плотность лучей слишком 419 маленькая, результаты не отображаются.

420 При сравнении карт групповых скоростей волн Рэлея на (рис. 6) и горизонтальных 421 сечений финальной трехмерной модели Vs на (рис. 10) можно видеть, что групповые 422 скорости на малых периодах соответствуют малым глубинам, а большие периоды 423 большим глубинам. Так, структура на глубине 1 км практически полностью определяется 424 групповой скоростью на периоде 2 с, на глубине 2 км - периодом 3 с, на глубине 6 км 425 периодом 7 с. Исключением является глубина 4 км, на которой происходит смешение 426 влияния групповых скоростей на периодах от 5 до 7 с, претерпевающих существенные 427 изменения.

428 На четырех вертикальных сечениях на (рис. 11 и 12) показаны аномалии 429 относительно референтной модели и абсолютные скорости. Как уже было указано выше, 430 глубины в полученной скоростной модели считаются относительно рельефа. По этой 431 причине, на малых глубинах слои с положительными и отрицательными аномалиями 432 следуют линии рельефа, хотя, фактически, эти слои соответствуют постоянной глубине в 433 полученной трехмерной модели. На больших глубинах влияние рельефа постепенно 434 уменьшается таким образом, что на нижней границе сечений скорости считаются 435 относительно плоской границы. Интерпретация полученной трехмерной модели Vs 436 приведена в разделе «Обсуждение результатов».

Синтетическое тестирование.

Для того, чтобы проверить пространственное разрешение полученных моделей и найти оптимальные значения параметров инверсии, мы провели серию синтетических тестов. Пример такого теста приведен на (рис.13). Стратегия тестирования состоит в выполнении нескольких последовательных шагов:

1. Синтетическая модель задается как сумма одномерной референтной модели и трехмерного распределения синтетических аномалий. В приведенном на (рис. 13) примере синтетическая модель представляла собой «шахматную доску», то есть чередующиеся квадратные аномалии размером 15 км и амплитудой $\pm 9 \%$. В данном случае мы исследуем горизонтальное разрешение; поэтому значения аномалий остаются неизменными на всех глубинах. Проблемы вертикального разрешения обсуждались при представлении алгоритма одномерной инверсии и демонстрировались на рис. 9.

2. Для данной синтетической скоростной модели строятся карты групповых скоростей для всех частот, используя алгоритм прямого моделирования [Herrmann, 1987]. 
алгоритм изгиба, тот же самый, что и при выполнении итеративной инверсии. Для этих лучей рассчитываются времена пробега, которые преобразуются в кажущиеся групповые скорости.

4. Восстановление начинается с расчета двумерных карт групповых скоростей для всего имеющегося набора частот.

5. Полученные карты групповых скоростей преобразуются в трехмерное распределение скорости Vs, используя точно такую же процедуру, как в случае инверсии реальных данных.

Результат восстановления синтетической модели, представленный на (рис. 13) в виде четырех горизонтальных сечений, показывает, что данная система наблюдения позволяет нам надежно восстанавливать аномалии на всех интервалах глубин. Вместе с тем амплитуда аномалий на глубоких сечениях существенно ниже величины, заданной в синтетической модели, что связано с понижением чувствительности поверхностных волн к глубинным неоднородностям.

Как отмечалось в параграфе «Оптимизация одномерной модели Vs», вертикальное разрешение в данном случае имеет определенные ограничения, главным образом связанные с малым количеством уравнений (шесть, по количеству задействованных периодов), участвующих в восстановлении скорости по глубине. На (рис. 14) показан результат синтетического тестирования, нацеленного на изучение вертикального разрешения. В этом случае синтетическая модель типа «шахматная доска» с аномалиями скорости размером $15 \mathrm{x} 2$ км была задана вдоль сечения А1B1, положение которого обозначено на (рис. 13). Можно видеть, что томографическая инверсия обеспечивает восстановление аномалий в верхних трех слоях до глубины около 5 км. В четвертом слое аномалии размазываются вниз, что говорит об ограниченном разрешении модели ниже глубины 6 км.

Таким образом, эти выявленные по результатам синтетического тестирования эффекты, связанные с ограничениями разрешающей способности метода, должны учитываться при интерпретации результатов инверсии реальных данных.

\section{ОБСУЖДЕНИЕ}

\section{Сравнение с предыдущими моделями.}

Прежде всего важно сравнить полученные в данной работе карты групповых скоростей и трехмерное распределение Vs с моделями из работы Green et al. [2020], построенными на основе тех же данных, но с использованием другого алгоритма томографии. Сразу следует напомнить, что в нашей работе использовались только станции, расположенные в непосредственной близости к Ключевской группе (рис. 1a), в то время как 
Green et al. [2020] задействовали все станции сети KISS, что объясняет большие размеры исследованной области в их случае. В их статье приведены карты групповых скоростей волн Рэлея для периодов 4, 5, 7 и 10 секунд. Следовательно, первые три карты можно сравнить с нашими, построенными для тех же периодов. На периодах 4 и 5 секунд модели показывают, в целом, те же особенности: низкоскоростные аномалии на западе и востоке

493 от КГВ и линейная высокоскоростная аномалия, протягивающаяся с юга на север по 494 основным вулканам группы. Вместе с тем в работе Green et al. [2020] эти особенности выглядят существенно более сглаженными. В нашей модели выявляется гораздо больше деталей, которые приурочены к конкретным вулканическим системам. На периоде 7 секунд в модели Green et al. [2020] наблюдается крупная низкоскоростная аномалия на западе от 498 КГВ и меньшая по размеру отрицательная аномалия на востоке. В районе вулканов у них 499 наблюдается некоторое повышение скорости. В нашей модели наблюдается схожее 500 строение, однако внутри КГВ вместо одной сильно сглаженной аномалии мы выделяем 501 более сложную структуру. Из этого сравнения можно сделать вывод, что обе модели 502 групповых скоростей, в целом, показывают непротиворечивые конфигурации крупных структур. Основные отличия заключаются в представлении более мелких структур, которые в модели Green et al. [2020] фактически не выделяются. Те же общие особенности и различия проявляются в финальных трехмерных моделях Vs.

Определенное соответствие наблюдается между моделью из работы Koulakov et al.

507 [2020], полученной на основе инверсии данных по объемным волнам, с картами групповых 508 скоростей на малых периодах и близповерхностными аномалиями $\mathrm{dVs}$, рассчитанными в результате настоящего исследования (рис. 15). Можно видеть, что во всех случаях крупные аномалии, отвечающие вулканическим структурам КГВ, выделяются одинаково. Некоторое различие наблюдается на периферии изучаемой области, что может быть связано с тем, что там разрешение обоих моделей падает, и увеличивается влияние случайного фактора. Тем не менее, из наличия явного соответствия основных аномалий, полученных независимо на основе принципиально различных типов данных, можно сделать вывод о достоверности выявленных структур.

\section{Проявления вулканических структур КГВ в томографических моделях.}

518 связанные с крупнейшими вулканическими постройками внутри КГВ. Наиболее яркая 519 высокоскоростная аномалия на всех интервалах глубин расположена под сросшимися 520 вулканами Ушковский и Крестовский. Можно определенно сказать, что на малых глубинах 521 (1 км) и малых периодах (2 c) высокоскоростная аномалия показывает основание крупного 522 базальтового щитового вулкана, начиная с которого здесь началось развитие вулканической 
системы 50-60 тысяч лет назад [Флеров, Овсянников, 1991; Флеров и др., 2017]. Данный

524 массив содержит в себе объем пород больший, чем в остальных вулканических постройках

525 КГВ вместе взятых. Вследствие своей большой массы, при накоплении часть материала данного массива могла постепенно погружаться вниз, чем можно объяснить наличие данной аномалии на больших глубинах. Тем не менее, маловероятно, что за время существования этой системы ее опускание в кору произошло до глубин 6 км и ниже, на которых прослеживается связанная с ней аномалия. По-видимому, начиная с определенного уровня, высокие скорости сейсмических волн обусловлены наличием большой концентрации застывших базальтовых даек, питавших этот вулкан по ходу его образования.

532 Представляется естественным, что для создания такого объемного вулканического тела система питания в верхней коре должна быть достаточно мощной, чтобы обеспечить приток

534 большого количества базальтового материала, и ее наличие должно проявляться в сейсмических скоростях.

Другим крупным вулканическим объектом, который на малых глубинах связан с высокоскоростной аномалией, является сросшийся вулканический комплекс Плоского и

538 Острого Толбачика. Как и в случае вулкана Ушковский, Толбачинский массив состоит из пород преимущественно базальтового состава [Churikova et al., 2015] и имеет чрезвычайно

540 большой объем. Именно это объясняет то, что высокоскоростная аномалия, точно 541 совпадающая с контурами массива, прослеживается до глубины 2 км от поверхности, то 542 есть примерно до уровня моря, с которого начиналась постройка этих вулканов. Ниже этого 543 уровня (сечения на глубине 4 и 6 км) высокоскоростная аномалия под Толбачиком 544 сменяется на низкоскоростную, что, вероятно, отражает наличие активной системы 545 подводящих каналов с высоким содержанием расплавов и флюидов. На западе от 546 Толбачика наблюдается яркая низкоскоростная аномалия, которая особенно четко 547 прослеживается на глубине 2 км. Она совпадает с аналогичной аномалией, полученной в 548 работе Green et al. [2020], в которой она интерпретируется как толстый слой осадков, 549 большей частью вулканогенных, который накопился на западной окраине КГВ вследствие 550 эруптивной активности вулканов группы.

Под потухшим вулканом Зимина обнаружена структура, аналогичная наблюдаемой

552 под Толбачиком. На малых глубинах контур вулкана точно совпадает с яркой высокоскоростной аномалией, отражающей наличие консолидированных изверженных

554 пород, из которых построен вулканический массив. Вместе с тем неожиданным является 555 то, что эта аномалия имеет схожие свойства с аномалией под Толбачиком, хотя породы 556 вулкана Зимина состоят по большей части из дацитов и андезитов [Флеров и др., 2019], и, 557 соответственно, должны проявляться в более низких скоростях, чем в случае базальтового 
вулкана Толбачик. На глубинах 4 и 6 км под вулканом Зимина наблюдаются

559 низкоскоростные аномалии, которые могли бы свидетельствовать о наличии активной

560 магматической системы. Однако отсутствие какой какой-либо сейсмичности и

561 фумарольной активности в районе вулкана Зимина, а также каких-либо следов

562 магматической активности в течение недавнего геологического прошло, противоречат

563 этому предположению. Таким образом, вопрос о природе аномалий под вулканом Зимина

564 на данный момент остается открытым.

565 Под кластером из трех сросшихся друг с другом вулканов Ключевской, Камень и

566 Безымянный наблюдается достаточно сложная структура. На малых глубинах (1 км)

567 Ключевской вулкан и потухший Камень тяготеют к высокоскоростной аномалии, которая,

568 впрочем, существенно менее четко выражена, чем в случаях Ушковского и Толбачинских

569 вулканов. Это можно объяснить тем, что в настоящее время активный и быстро растущий

570 вулкан Ключевской, хоть и состоит преимущественно из базальтовых пород, имеет в своей

571 постройке достаточно высокое содержание рыхлой пирокластики, не успевшей

572 консолидироваться в высокоскоростной материал. Вулкан Камень на глубине 1 км (около

5732 км выше уровня моря) связан с небольшой высокоскоростной аномалией, которая

574 является следствием того, что Камень давно является потухшим и состоит из

575 консолидированных изверженных пород. Вместе с тем, относительно малая амплитуда этой

576 аномалии может быть объяснена с тем, что по составу этот вулкан тяготеет к андезитам,

577 имеющим более низкие скорости, чем базальты. Третий вулкан кластера, Безымянный, на

578 глубине 1 км (и особенно на карте групповых скоростей для периода 2 с) находится в районе

579 локального понижения скорости, что можно связать с большим количеством рыхлой

580 пирокластики, образовавшейся вследствие взрывного характера извержений этого вулкана.

581 Также нужно учитывать андезит-дацитовый состав продуктов Безымянного,

582 проявляющийся в пониженных сейсмических скоростях по сравнению с более основными

583 породами у других вулканов кластера.

584 На глубине 2 км кластер Ключевской-Камень-Безымянный оказывается внутри 585 низкоскоростной аномалии. На вертикальных сечениях через данный кластер видно, что 586 эта аномалия возникает для того, чтобы «уплостить» изолинии абсолютных скоростей 587 около уровня моря. Если бы этой аномалии не было, тогда изолиния скорости 2 км/с, 588 расположенная примерно на уровне моря (на глубине 0), следовала бы по контуру рельефа 589 и под кластером высоких вулканов оказалась бы на уровне 2-3 км выше уровня моря. 590 Полученный результат показывает, что данный вулканический кластер является 591 постройкой с относительно низкими абсолютными скоростями, стоящей на 592 горизонтальном высокоскоростном фундаменте. На глубине 4 км под этими тремя 
вулканами наблюдается высокоскоростная аномалия, которая может отражать наличие

594 относительного повышения уровня фундамента на данной глубине (0-2 км под уровнем 595 моря). На глубине 6 км под вулканами Безымянный и Камень наблюдается яркая 596 низкоскоростная аномалия, которая, вероятно, указывает на малоглубинный 597 магматический очаг в верхней коре, питающий современные извержения вулкана 598 Безымянный. Аналогичная аномалия в средней и верхней коре под вулканом Безымянный 599 была выявлена в сейсмической модели, построенной на базе объемных волн [Koulakov et 600 al., 2017].

Неожиданным является расположение вулкана Удина внутри низкоскоростной аномалии, доминирующей на всех глубинах (за исключением 4 км), хотя по свойствам эта, как предполагалось ранее, потухшая вулканическая постройка должна проявляться 604 аналогичным вулкану Зимина образом. Подобная низкоскоростная аномалия прослеживается в модели, построенной на базе данных по объемным волнам [Koulakov et al., 2020]. В какой-то степени наличие здесь пониженных скоростей можно объяснить андезит-дацитовым составом этого вулкана, аналогичным вулкану Безымянный. В момент проведения эксперимента KISS не было никаких свидетельств какой-либо активности вулкана Удина, и он причислялся во всех базах данных к полностью потухшим. Поэтому яркая низкоскоростная аномалия Vs на глубине 6 км под этим вулканом (фактически, на 611 глубине 3-4 км) не находила объяснения с учетом имевшейся к тому времени информации. 612 Однако в декабре 2017 года на этом вулкане началась сейсмическая активизация, которая 613 продолжалась больше двух лет и вызвала определенные беспокойства по поводу 614 возможности его извержения [Кугаенко и др., 2020]. Для точной локализации сейсмичности 615 под этим вулканом были установлены на срок три месяца четыре станции, которые выявили 616 более 300 вулканотектонических событий непосредственно под Удиной [Koulakov et al., 617 2019]. Также на базе этих данных была проведена томографическая инверсия, которая 618 выявила под вулканом Удина аномальную зону с повышенными скоростями продольных 619 волн (Vp) и пониженными Vs. По интенсивности и расположению эта аномалия dVs 620 соответствует тому, что мы наблюдаем в независимо рассчитанной модели по 621 поверхностным волнам. На основании полученной в этих исследованиях информации 622 можно сделать предположение, что под вулканом Удина на глубине 4-6 км под уровнем 623 моря существует магматический очаг, который в течение многих тысяч лет находился в 624 пассивном состоянии, однако в последние годы стал проявлять признаки активности. 625 Вероятно, наблюдаемая в последние годы активизация вулкана Удина постепенно затихнет, 626 как происходило во множестве других подобных случаев. Вместе с тем нельзя исключать 
возможность извержения этого вулкана, которо катастрофичным, как и взрыв Безымянного в 1956 году.

\section{ЗАКЛЮЧЕНИЕ}

Данное исследование является по сути повторением другой работы [Green et al., 2020], выполненной недавно и посвященной изучению строения верхней коры Ключевской группы вулканов на основе данных по поверхностным волнам. Базовые методические подходы и источник исходных данных (сеть KISS) в этих двух исследованиях были одними и теми же. Однако конкретные алгоритмы томографической инверсии были существенно различны. Green et al. [2020] использовали подход случайного поиска решения на основе метода Монте-Карло, в то время как в настоящей работе мы использовали итеративные схемы с линеаризованной матричной инверсией. При том, что обе работы предоставили, в целом, непротиворечивые результаты для крупных форм, наша модель является более детализированной, что позволяет выявить важную новую информацию о строении вулканических комплексов в КГВ.

Можно видеть, что крупные базальтовые постройки Ушковский-Крестовский и

643 Толбачик приурочены к ярким высокоскоростным аномалиям на малых глубинах. Однако

644 на больших глубинах структура под спящим Ушковским вулканом остается 645 высокоскоростной, а под Толбачиком мы наблюдаем аномалию с пониженными 646 скоростями. Это отражает состояние системы подводящих каналов, которые 647 принципиально отличаются под спящим и действующим вулканами.

648 В районе кластера вулканов Ключевской-Камень-Безымянный наблюдается сложная 649 структура, которая значительно варьируется как по латерали, так и по глубине. Сечение с 650 абсолютными скоростями показывает, что постройки этих вулканов представляют собой 651 относительно низкоскоростные тела, которые расположены на плоском высокоскоростном 652 фундаменте, что, возможно, связано с достаточно быстрым процессом их формирования и 653 слабой консолидированностью изверженных пород. Низкоскоростная аномалия под 654 вулканом Безымянный на глубине 6 км, вероятно, приурочена к малоглубинному магматическому очагу, который ответственен за текущие извержения вулкана.

Неожиданно, для вулкана Удина, который до недавнего времени считался потухшим, обнаружена низкоскоростная аномалия, которая становится наиболее интенсивной на глубине 6 км. Вместе с тем объяснить эту структуру можно с учетом информации о сейсмической активизации этого вулкана, которая началась в декабре 2017

660 года и продолжается до настоящего времени. Локальная томографическая модель, 661 построенная для этого вулкана при помощи данных, полученных с небольшой временной 
сети станций, показала аналогичную низкоскоростную аномалию Vs, расположенную в

663 районе активной сейсмичности [Koulakov et al., 2019]. Это указывает на наличие под вулканом Удина магматического очага, который существовал там и в 2015-2016 году, когда работала сеть KISS, и который активизировался в конце 2017 года. Нельзя исключать, что эта активизация приведет к извержению, однако более вероятно, что она постепенно затихнет, как происходило во множестве случаев «неудавшейся магматической активности» в мире.

669

Богоявленская, Г. Е., Брайцева, О. А., Мелекесцев, И. В., Максимов, А. П., Иванов, Б. В. Вулкан Безымянный // Действующие вулканы Камчатки, т.1, под ред. Федотова С.А. и Масуренкова Ю. П. М. Москва, ФГУП изд-во «Наука», 1991, с. 168-197.

Добрецов Н. Л., Кулаков И. Ю., Литасов Ю. Д. Пути миграции магм и флюидов и составы вулканических пород Камчатки // Геология и геофизика, 2012, т. 53 (12), с. 16331661.

Ермаков В. А., Важеевская А. А. Вулканы Острый и Плоский Толбачик // Бюллетень вулканологических станций, 1973, №. 49, с. 43-53.

Кугаенко Ю. А., Салтыков В. А., Кулаков И. Ю., Павлов В. М., Воропаев П. В., Абкадыров И. Ф., Комзелева В. П. Развитие магматической системы под Удинским вулканическим комплексом (Камчатка) по сейсмическим данным 2017-2019 гг. // Геология и геофизика, 2020, doi: 10.15372/GiG2019160.

Кулаков И. Ю., Добрецов Н. Л., Бушенкова Н. А., Яковлев А. В. Форма слэбов в зонах субдукции под Курило-Камчатской и Алеутской дугами по данным региональной томографии // Геология и геофизика, 2011, т. 52 (6), с. 830-851.

Кулаков И. Ю., Кукарина Е. В., Гордеев Е. И., Чебров В. Н., Верниковский В. А. Магматические источники в мантийном клине под вулканами Ключевской группы и влк. Кизимен (Камчатка) по данным сейсмической томографии // Геология и геофизика, 2016, т. 57 (1), c. 109-124.

Лаверов Н. П., Добрецов Н. Л., Богатиков О. А., Бондур В. Г., Гурбанов А. Г., 691 Карамурзов Б. С., Коваленко В. И., Мелекесцев И. В., Нечаев Ю. В., Пономарев В. В., 692 Рогожин Е. А., Собисевич А. Л., Собисевич Л. Е., Федотов С. А., Хренов А. П., Ярмолюк В. 693 В. Новейший и современный вулканизм на территории России. Москва, ФГУП изд-во «Наука», 2005, 604 с. очерк вулканов Северной группы и Срединного хребта // Действующие вулканы Камчатки, 
697 т.1, под ред. Федотова С. А. и Масуренкова Ю. П. М. Москва, ФГУП изд-во «Наука», 1991, 698 c. $74-83$.

699 Низкоус И. В., Санина И. А., Кисслинг Э., Гонтовая Л. И. Скоростные свойства 700 литосферы переходной зоны океан-континент в районе Камчатки по данным сейсмической томографии // Физика Земли, 2006, № 4, с. 18-29.

Овсянников А. А., Хренов А. П., Муравьев Я. Д. Современная фумарольная 703 деятельность на вулкане Дальний Плоский // Вулканология и сейсмология, 1985, № 5, с. 9798.

Певзнер М. М., Волынец А. О., Лебедев В. А., Бабанский А. Д., Коваленко Д. В., Костицын Ю. А., Толстых М. Л., Кущева Ю. В. Начало вулканической активности в пределах Срединно-метаморфического массива (Срединный хребет, Камчатка) // Доклады Академии наук, 2017, т. 475 (5), с. 546-550.

Пономарева В. В., Чурикова Т. Г., Мелекесцев И. В., Брайцева О. А., Певзнер М. М., Сулержицкий Л. Д. Позднеплейстоцен-голоценовый вулканизм Камчатки // Изменение окружающей среды и климата: природные и связанные с ними техногенные катастрофы. Том II. Новейший вулканизм северной Евразии: закономерности развития, вулканическая опасность, связь с глубинными процессами и изменениями природной среды и климата. Москва, изд-во ИГЕМ РАН, 2008, с. 19-40. сейсмическая активизация 2017-2018 гг // Вестник Камчатской региональной организации Учебно-научный центр. Серия: Науки о Земле, 2018, № 1 (37), с. 5-7. Скоростное строение и напряженно-деформированное состояние земной коры в районе Ключевской группы вулканов Камчатки // Вулканология и сейсмология, 2001, № 1, с. 4959.

Федотов С. А. Большое трещинное Толбачинское извержение. Камчатка. 1975-1976. Москва, ФГУП изд-во «Наука», 1984, 637 с.

Федотов С. А., Жаринов Н. А., Гонтовая Л. И. Магматическая питающая система Ключевской группы вулканов (Камчатка) по данным об её извержениях, землетрясениях, деформациях и глубинном строении // Вулканология и сейсмология, 2010, № 1, с. 3-35.

Флеров Г. Б., Овсянников А. А. Вулкан Ушковский // Действующие вулканы 728 Камчатки, т.1, под ред. Федотова С.А. и Масуренкова Ю. П. М. Москва, ФГУП изд-во 729 «Наука», 1991, с. 156-167. 

геология, петрохимия, минералогия и петрогенезис пород (Ключевская группа вулканов, Камчатка) // Вулканология и сейсмология, 2017, № 4, с. 30-47.

Флеров Г. Б., Чурикова Т. Г., Гордейчик Б. Н., Ананьев В. В. Вулканический массив Зиминых сопок: геология и минералогия пород (Ключевская группа вулканов, Камчатка) // Вестник Камчатской региональной организации Учебно-научный центр. Серия: Науки о Земле, 2019, № 4 (44), с. 19-34.

Хренов А. П., Двигало

В. Н., Кирсанов И. Т., Федотов С. А., Горельчик В. И.,

Жаринов Н. А. Вулкан Ключевской // Действующие вулканы Камчатки, т.1, под ред. Федотова С. А. и Масуренкова Ю. П. М. Москва, ФГУП изд-во «Наука», 1991, с. 106-145.

Хубуная С. А., Гонтовая Л. И., Соболев А. В., Низкоус И. В. Магматические очаги под Ключевской группой вулканов (Камчатка) // Вулканология и сейсмология, 2007, № 2, c. $32-54$.

Чебров В. Н., Дрознин Д. В., Кугаенко Ю. А., Левина В. И., Сенюков С. Л., Сергеев В. А., Шевченко Ю. В., Ящук В. В. Система детальных сейсмологических наблюдений на Камчатке в 2011 г // Вулканология и сейсмология, 2013, № 1, с. 18-40.

Alexeiev D. V., Tsukanov N. V., Gaedicke C., Freitag R. Collision of the Kronotskiy arc at the NE Eurasia margin and structural evolution of the Kamchatka-Aleutian junction // International Journal of Earth Sciences, 2006, vol. 95 (6), p. 977-993.

Avdeiko G. P., Savelyev D. P., Palueva A. A., Popruzhenko S. V. Evolution of the KurileKamchatkan volcanic arcs and dynamics of the Kamchatka-Aleutian junction // Volcanism and Subduction: The Kamchatka Region. Geophysical Monograph Series, vol. 172, edited by Eichelberger J., Gordeev E., Kasahara M., Izbekov P., Lees J. M. Washington D.C., published by American Geophysical Union, 2007, p. 37-55.

Belousov A., Belousova M., Volynets A., Melnikov D., Edwards B. Overview of the precursors and dynamics of the 2012-13 basaltic fissure eruption of Tolbachik Volcano, Kamchatka, Russia // Journal of Volcanology and Geothermal Research, 2015, vol. 307, p. 22-37.

Dorendorf F., Wiechert U., Wörner G. Hydrated sub-arc mantle: a source for the Kluchevskoy volcano, Kamchatka/Russia // Earth and Planetary Science Letters, 2000, vol 175 (12), p. 69-86.

Campillo M., Sato H., Shapiro N. M., van der Hilst R. D. New developments on imaging and monitoring with seismic noise // Comptes Rendus Geoscience, 2011, vol 343 (8-9), p. 487495.

Churikova T. G., Gordeychik B. N., Edwards B. R., Ponomareva V. V., Zelenin E. A. The 
the 2012-2013 eruption // Journal of Volcanology and Geothermal Research, 2015, vol 37, p. 321.

Girina O. A. Chronology of Bezymianny Volcano activity, 1956-2010 // Journal of Volcanology and Geothermal Research, 2013, vol. 263, p. 22-41.

Gorbatov A., Domínguez J., Suárez G., Kostoglodov V., Zhao D., Gordeev E. Tomographic imaging of the P-wave velocity structure beneath the Kamchatka peninsula // Geophysical Journal International, 1999, vol. 137 (2), p. 269-279.

Gorbatov A., Fukao Y., Widiyantoro S., Gordeev E. Seismic evidence for a mantle plume oceanwards of the Kamchatka-Aleutian trench junction // Geophysical Journal International, 2001, vol. 146 (2), p. 282-288.

Green R. G., Sens- Schönfelder C., Shapiro N., Koulakov I., Tilmann F., Dreiling J., Luehr B., Jakovlev A., Abkadyrov I., Droznin D., Gordeev E. Magmatic and sedimentary structure beneath the Klyuchevskoy volcanic group, Kamchatka, from ambient noise tomography // Journal of Geophysical Research: Solid Earth, 2020, vol 125 (3), e2019JB018900. https://doi.org/ 10.1029/2019JB018900.

Herrmann R. B. Computer programs in seismology: An evolving tool for instruction and research, 1987 , Saint Louis University [Available at http://www.eas.slu.edu/People/RBHerrmann/CPS330.html]

Ivanov I., Koulakov I., West M., Jakovlev A., Gordeev E., Senyukov S., Chebrov V. Magma sources beneath the Klyuchevskoy and Bezymianny volcanoes inferred from local earthquake seismic tomography // Journal of Volcanology and Geothermal Research, 2016, vol. 323 , p. 62-71.

Jiang, G., Zhao D., Zhang G. Seismic tomography of the Pacific slab edge under Kamchatka // Tectonophysics, 2009, vol. 465 (1-4), p. 190-203.

Koulakov I., Gordeev E. I., Dobretsov N. L., Vernikovsky V. A., Senyukov S., Jakovlev

A. Feeding volcanoes of the Kluchevskoy group from the results of local earthquake tomography // Geophysical Research Letters, 2011, vol. 38 (9), L09305, doi:10.1029/2011GL046957.

Koulakov I., Gordeev E.I., Dobretsov N. L., Vernikovsky V. A., Jakovlev A., Jaxybulatov K., Senyukov S. Rapid changes in magma storage beneath the Klyuchevskoy group of volcanoes inferred from time-dependent seismic tomography // Journal of Volcanology and Geothermal Research, 2013, vol. 263, p. 75-91.

Koulakov I., Maksotova G., Jaxybulatov K., Kasatkina E., Shapiro N. M., Luehr B. G., El Khrepy S., Al-Arifi N. Structure of magma reservoirs beneath Merapi and surrounding volcanic centers of Central Java modeled from ambient noise tomography // Geochemistry, Geophysics, 

E. I., Shapiro N., Al Arifi N., El Khrepy S., Droznina S., Kugaenko Y., Senyukov S., Kulakov R. I., West M. Three different types of plumbing system beneath the neighboring active volcanoes of Tolbachik, Bezymianny, and Klyuchevskoy in Kamchatka // Journal of Geophysical Research: Solid Earth, 2017, vol. 122 (5), p. 3852-3874.

Koulakov I., Komzeleva V., Abkadyrov I., Kugaenko Y., El Khrepy S., Al Arifi N. Unrest of the Udina volcano in Kamchatka inferred from the analysis of seismicity and seismic tomography // Journal of Volcanology and Geothermal Research, 2019, vol. 379, p. 45-59.

Koulakov I., Shapiro N., Sens-Shoenefelder C., Luehr B., Gordeev E., Jakovlev A., Abkadyrov I., Chebrov D., Droznina S., Senyukov S., Novgorodova A., Stupina T. Mantle and crustal sources of magmatic activity of Klyuchevskoy and surrounding volcanoes in Kamchatka inferred from earthquake tomography // Journal of Geophysical Research: Solid Earth (submitted), 2020 .

Lees J. M., Symons N., Chubarova O., Gorelchik V., Ozerov A. Tomographic Images of 814 Klyuchevskoy Volcano P-Wave Velocity. // Volcanism and Subduction: The Kamchatka Region. 815 Geophysical Monograph Series, vol.172, edited by Eichelberger J., Gordeev E., Kasahara M., 816 Izbekov P., Lees J. M. Washington D.C., published by American Geophysical Union, 2007, p. 293-302.

818 Levshin A. L., Yanovskaya T. B., Lander A. V., Bukchin B. G., Barmin M. P., Ratnikova 819 L. I., Its E. N. Recording, identification, and measurement of surface wave parameters // Seismic 820 Surface Waves in a Laterally Inhomogeneous Earth. Modern Approaches in Geophysics, vol 9., edited by Keilis-Borok V. I. Dordrecht, published by Springer, 1989, p. 131-182.

Mordret A., Landès M. GUI_FTA_v2p1, 2013, Institut de Physique du Globe de Paris.

Nolet G. Seismic wave propagation and seismic tomography // Seismic Tomography. Seismology and Exploration Geophysics, vol 5, edited by Nolet G. Dordrecht, published by Springer, 1987, p. 1-23.

Ozerov A. Yu., Bogoyavlenskaya G. E., Ariskin A. A., Karpenko S. F., Kyle Ph. Petrological-geochemical model for genetic relationships between basaltic and andesitic magmatism of Klyuchevskoi and Bezymyannyi volcanoes, Kamchatka // Petrology, 1997, vol. 5 (6), p. 550-569.

Ozerov A. Y., Firstov P. P., Gavrilov V. A. Periodicities in the Dynamics of Eruptions of Klyuchevskoi Volcano, Kamchatka // Volcanism and Subduction: The Kamchatka Region. Geophysical Monograph Series, vol.172, edited by Eichelberger J., Gordeev E., Kasahara M., Izbekov P., Lees J. M. Washington D.C., published by American Geophysical Union, 2007, p. 283-291. 
Paige C. C. and Saunders M. A. LSQR: An algorithm for sparse linear equations and sparse least squares // ACM Transactions on Mathematical Software (TOMS), 1982, vol. 8(1), p. 43-71.

Portnyagin M., Hoernle K., Hauff F., Avdeiko G., Werner R., Bindeman I., Uspensky V.,

838 Garbe-Schönberg D. Transition from arc to oceanic magmatism at the Kamchatka-Aleutian 839 junction // Geology, 2005, vol. 33 (1), p. 25-28.

840 Ritzwoller M. H., Levshin A. L. Eurasian surface wave tomography: Group velocities // 841 Journal of Geophysical Research: Solid Earth, 1998, vol. 103 (B3), p. 4839-4878.

842 Shapiro N. M., Campillo M., Stehly L., Ritzwoller M. H. High resolution surface wave 843 tomography from ambient seismic noise // Science, 2005, vol. 307 (5715), p. 1615-1618.

844 Shapiro N. M., Gusev A. A., Gordeev E. I., Droznin D. V., Droznina S. Ya., Senyukov S.

845 L. Deep and shallow long-period volcanic seismicity linked by fluid-pressure transfer // Nature 846 Geoscience, 2017b, vol. 10 (6), p. 442-445.

847 Shapiro N. M., Sens-Schönfelder C., Lühr B. G., Weber M., Abkadyrov I., Gordeev E. I., 848 Koulakov I., Jakovlev A., Kugaenko Y. A., Saltykov V. A. Understanding Kamchatka's 849 extraordinary volcano cluster // EOS: transactions, American Geophysical Union, 2017a, vol. 98 850 (7), p. 12-17.

Van Manen S. M., Dehn J., Blake S. Satellite thermal observations of the Bezymianny lava 852 dome 1993-2008: Precursory activity, large explosions, and dome growth // Journal of 853 Geophysical Research: Solid Earth, 2010, vol. 115(B8), B08205, doi:10.1029/2009JB006966.

854 Yogodzinski G. M., Lees J. M., Churikova T. G., Volynets O. N., Dorendorf F., Wöerner 855 G. Geochemical evidence for the melting of subducting oceanic lithosphere at plate edges // 856 Nature, 2001, vol. 409 (6819), p. 500-504. 